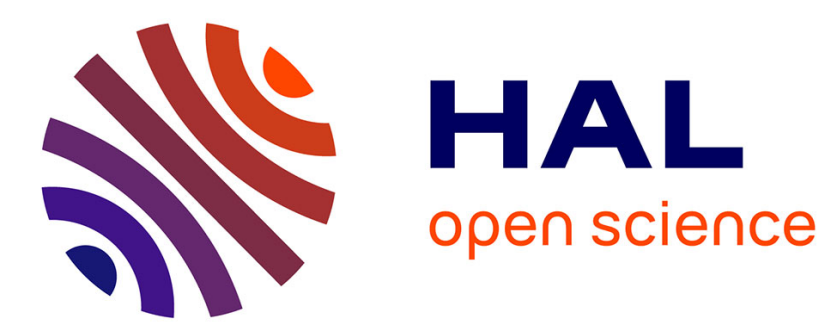

\title{
EBIC INVESTIGATIONS OF EXTENDED DEFECTS IN CdTe
}

\author{
G. Panin, E. Yakimov
}

\section{To cite this version:}

G. Panin, E. Yakimov. EBIC INVESTIGATIONS OF EXTENDED DEFECTS IN CdTe. Journal de Physique IV Proceedings, 1991, 01 (C6), pp.C6-181-C6-186. 10.1051/jp4:1991627 • jpa-00250712

\section{HAL Id: jpa-00250712 https://hal.science/jpa-00250712}

Submitted on 1 Jan 1991

HAL is a multi-disciplinary open access archive for the deposit and dissemination of scientific research documents, whether they are published or not. The documents may come from teaching and research institutions in France or abroad, or from public or private research centers.
L'archive ouverte pluridisciplinaire HAL, est destinée au dépôt et à la diffusion de documents scientifiques de niveau recherche, publiés ou non, émanant des établissements d'enseignement et de recherche français ou étrangers, des laboratoires publics ou privés. 


\title{
EBIC INVESTIGATIONS OF EXTENDED DEFECTS IN CdTR
}

\author{
G.N. PANIN and E.B. YAKIMOV
}

Institute of Microelectronics Technology and High Purity Materials, USSR Academy of Sciences, Chernogolovka, Moscow District 142432, USSR

\begin{abstract}
The EBIC and remote contact EBIC (REBIC) techniques have been used to reveal grain boundaries and precipitates in cdTe crystals and to study their recombination contrast as a function of the electron beam parameters and temperature. The results obtained are discussed taking into account the defect charge state and the recombination properties of their environment.
\end{abstract}

\section{Introduction}

Numerous technical applications of cdTe crystals are limited by the lack of detailed knowledge about the properties of electrically active defects and extended defects in particular. To detect and characterize such defects with the high spatial resolution the electron beam-induced current (EBIC) mode of a scanning electron microscope (SEM) is extensively used [1,2]. From these investigations it is well known that the EBIC contrast of extended defects strongly depends on the charge state of the defects $[3,4]$ and on their interaction with other lattice defects $[5,6]$. For example, it was shown that $\mathrm{Te}$ precipitates essentially influence the recombination activity of grain boundaries in caTe [7]. Therefore, to understand the mechanisms of the EBIC contrast formation it is necessary to carry out measurements of the defect contrast dependence on an incident beam current, primary electron energy, temperature etc. In the present work the EBIC technique has been used to study extended defects in caTe crystals. It has been shown that the dependence of the EBIC contrast on excitation conditions is determined by a difference in the electrical activity of the defects under study and their environment.

\section{Experimental}

$$
\text { p-cdTe crystals with shallow acceptor concentration of about }
$$
$10^{15} \mathrm{~cm}^{-3}$ grown by Bridgman technique were used for investigations. From these crystals samples with the dimensions $3 \times 3 \times 10 \mathrm{~mm}^{3}$ were cut. These samples were polished mechanically and chemically in the 
solution of $8 \% \mathrm{Br}$ in $\mathrm{HBr}$. After ion milling by $\mathrm{Ar}^{+}$with the energy about $600 \mathrm{eV}$ barrier structures were formed on the top surface of the samples by Al evaporation of about $50 \mathrm{~nm}$ thick. The ohmic contacts were formed on the opposite surface by Au chemical deposition. The EBIC contrast value was calculated as $C=\left(I_{0}-I_{d}\right) / I_{0}$, where $I_{0}$ and $I_{d}$ are induced current values when electron beam is far from the defect and on it, respectively. For the REBIC measurements the ohmic contacts were deposited on the opposite sides of the samples. In this case the signal is formed as a result of separation of created by an electron beam electron-hole pairs in the electric field of charged defects. Preliminary analysis of the samples under investigation was carried out by selective chemical etching and $x-r a y$ microanalysis. Grain boundaries, sub-grain boundaries, twins and some large enough (up to $10 \mu \mathrm{m}$ ) Te-rich precipitates in the matrix as well as near the extended defects were revealed.

\section{Results and discussion}

The results obtained have shown that practically all defects revealed by chemical etching, i.e. grain boundaries, sub-grain boundaries, twins, Te-rich precipitates and some other unidentified defects, can be seen in EBIC mode. These defects are charged at room temperature that can be shown by the REBIC investigations (Fig.1) which allow

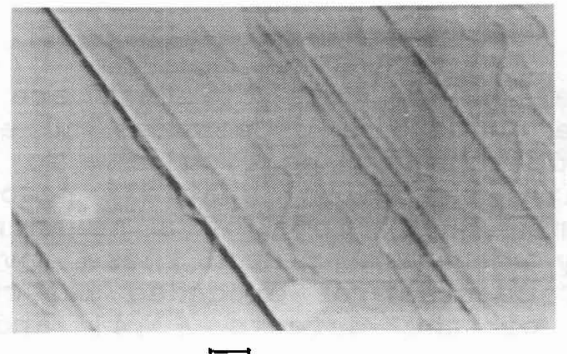

$100 \mu \mathrm{m}$

a)

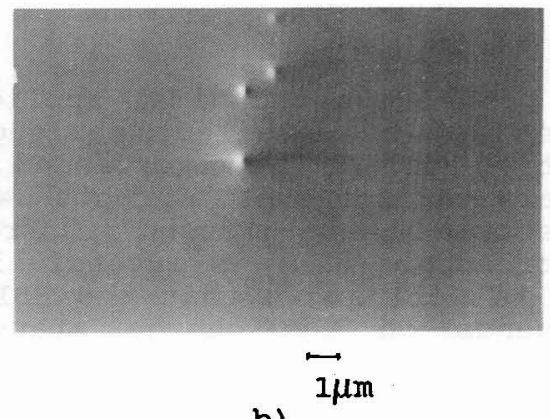

b)

Fig. 1 REBIC images of sub-grain boundaries and twins (a) and precipitate-like defects in caTe crystal (b) $\left(E_{b}=25 \mathrm{keV}, I_{b}=10^{-10} \mathrm{~A}\right.$ ).

built-in electric fields in the crystals to be revealed $[8,9]$. It should be stressed that the REBIC gives also a possibility to study the dependence of the potential barriers formed near the charged defects on an excitation level. Our investigations have shown that some defects have a very stable potential barrier which exists up to the beam currents of about $10^{-8} \mathrm{~A}$. This stability can be explained by minority carrier transport along the defects or by an enhanced recombination inside the depletion region of the defect [10]. In CdTe crystals investigated both effects take place.

Indeed, many defects are surrounded by an impurity atmosphere or by more complex defects. For example, Fig.2 shows the EBIC images of two twins and a Te precipitate formed near them. It is easy to see 
that their EBIC contrast is strongly inhomogeneous. The beam current dependences of the EBIC contrast for these defects are different in different regions. A characteristic feature of these dependences is that the defect contrast decreases as the beam current increases. This can be explained by a defect potential barrier decrease with the increase of the excitation level $[3,4]$. However, the barrier
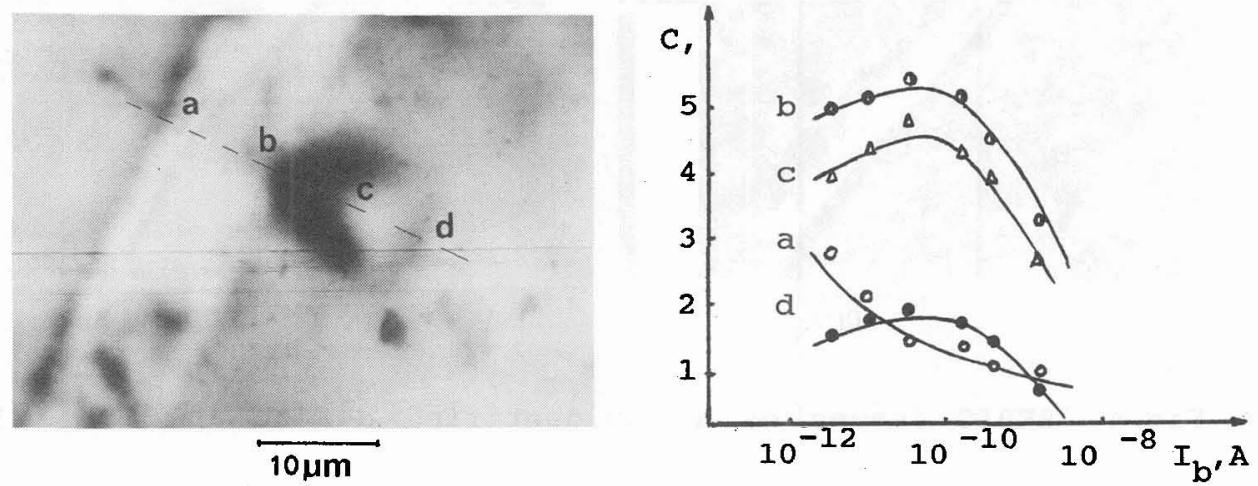

Fig.2 EBIC images and incident beam current dependence of EBIC contrast $\left(E_{b}=25 \mathrm{keV}\right)$ for twin (a) and for different regions of the Te precipitate $(b, c, d)$.

stability in different regions of these complex defects is different. In the range of low currents a decrease in the EBIC contrast with the beam current can be observed for the precipitate (Fig.1, curves $b, c, d)$. This may be accounted for by the presence of centers with shallower levels which might capture the majority carriers and hence their capture cross-section may increase with the beam current.

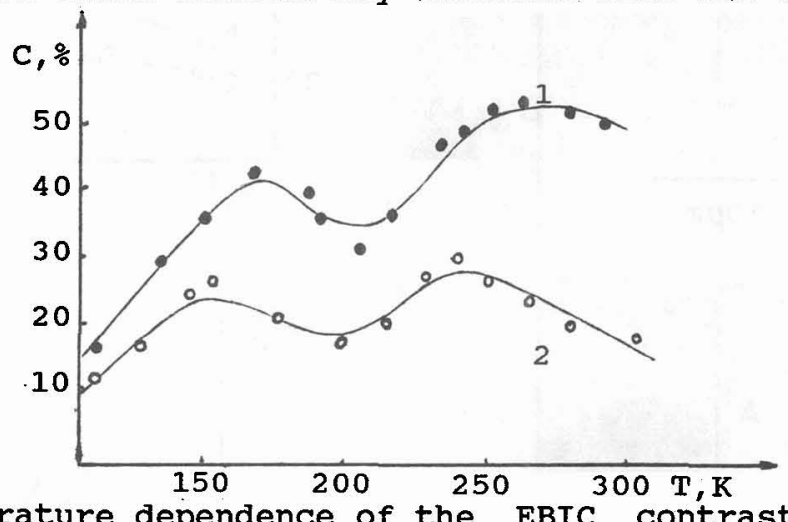

Fig.3. Temperature dependence of the EBIC contrast of a precipitate (1) and a subboundary (2)

Different dependence of the EBIC contrast on the excitation level indicates that the properties of the defect environment may differ from those of the defect itself. One more example of such behavior is presented in Fig.3 where the temperature dependences of the EBIC contrast with two maxima are shown. our investigations show that at least in some cases such dependences are a result of different temperature dependencies of different parts of the defect. It is illustrated in Fig.4 where one more barrier appears on the REBIC defect image at lower temperatures. It should be noted that on this REBIC image at a low temperature the contrast of sub-grain bondaries 
and twins is disappeared. This indicates that at the excitation conditions used a potential barrier near these defects is strongly decreased. In the same time for some defects a potential barrier can increase (Fig.4).

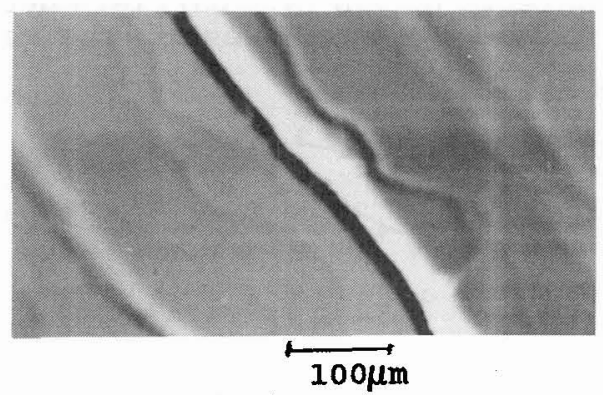

a)

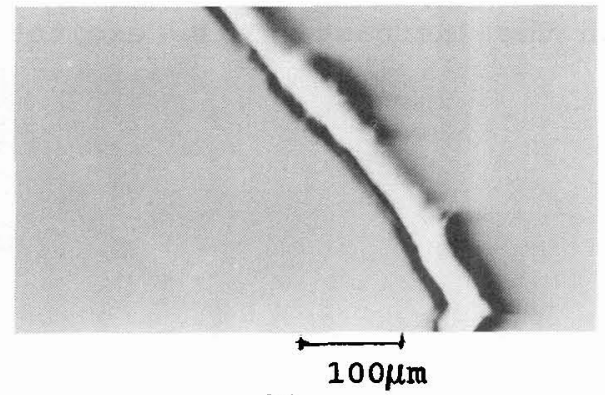

b)

Fig.4. REBIC images of an unidentified defect at $300 \mathrm{~K}$ (a) and 170K (b).

The difference in the recombination activity of different parts of the defect stipulates some peculiarities in the contrast dependence on an incident beam energy. Thus, Fig.5 shows cdTe crystal images in

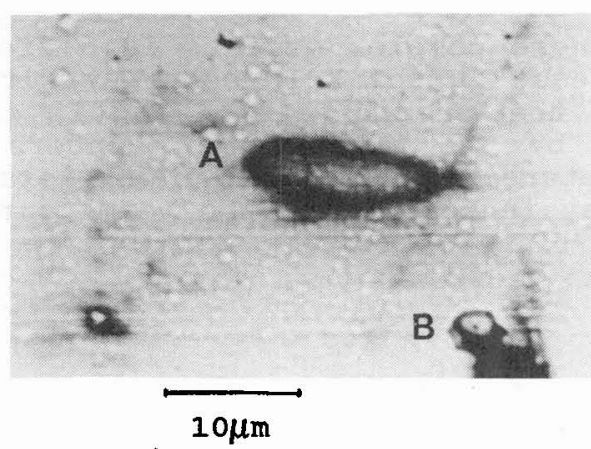

a)

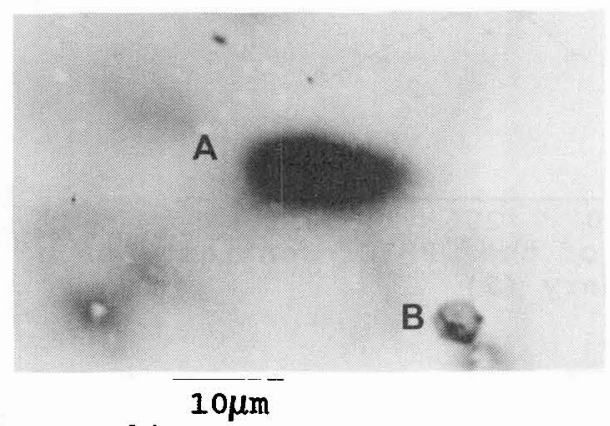

b)

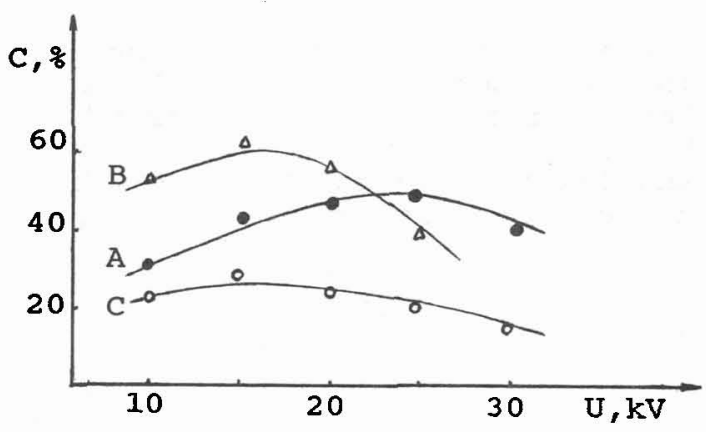

c)

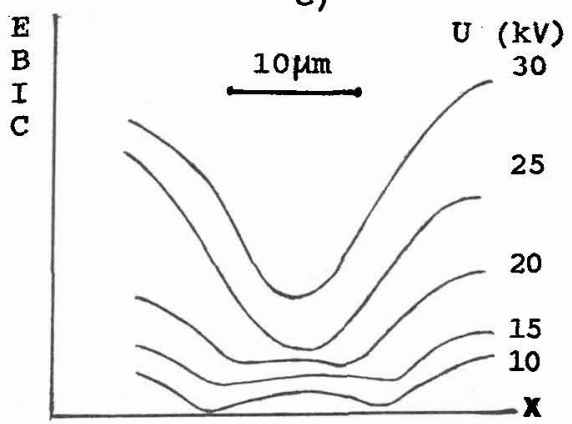

d)

Fig. 5 EBIC images at $U=10 \mathrm{kV}$ (a), $U=30 \mathrm{kV}$ (b) and dependence of the EBIC contrast on an accelerating voltage of different precipitate-like defects $(A, B)$. and a sub-grain boundary $C$ (C) and contrast profiles for a precipitate (A) at $I_{b}=10^{-10} A$ (d). 
the EBIC mode at different accelerating voltages. At $U_{b}=10 \mathrm{kV}$ it is clearly seen that a defect A consists of two regions of different recombination activities. The induced current profiles obtained at different accelerating voltages suggest that the minority carrier lifetime inside the defect is longer than in the region surrounding it. The dependence of the EBIC contrast of this defect on the accelerating voltage is non-monotonous and is shifted towards higher accelerating voltages as compared to that of another precipitate $B$ and of a subboundary $c$. It should be mentioned that for dislocations in CdTe the maxima in the contrast dependence on the beam energy were obtained to depend on the relation between the recombination efficiencies inside and outside the depletion region of a schottky diode $[11,12]$.

Another interesting feature of the EBIC defect images is a bright contrast which appears at rather high accelerating voltages (Fig.6).

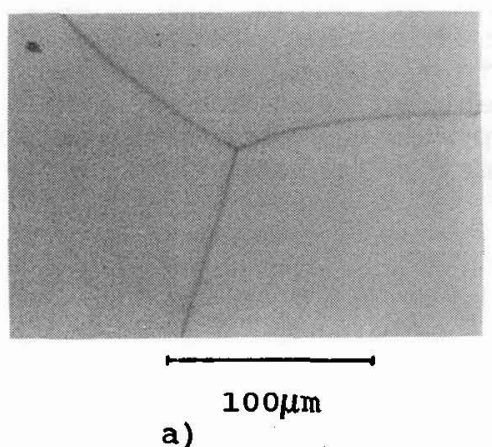

Fig. 6 EBIC images of grain boundaries at accelerating voltages of $20 \mathrm{kV}(\mathrm{a}), 30 \mathrm{kV}$ (b).

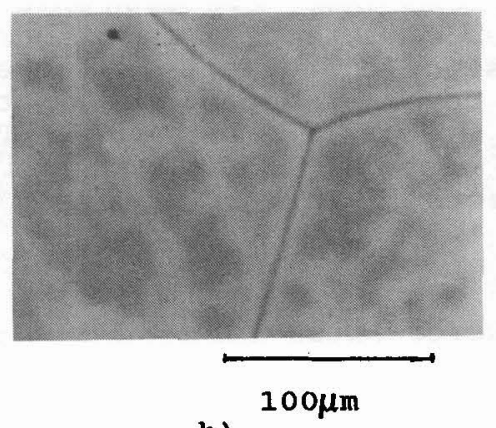

b)

At lower voltages the bright contrast disappears while a dark one remains. At low temperatures the bright contrast is seen more clearly along the boundaries when the induced current decreases in grains as a result of temperature decrease. It may be explained by the gettering effect of grain boundaries, but our REBIC investigations show that these grain boundaries are charged that may cause a transport of minority carriers along them. In some cases extended defects may bring about an inversion of the conductivity type in the region

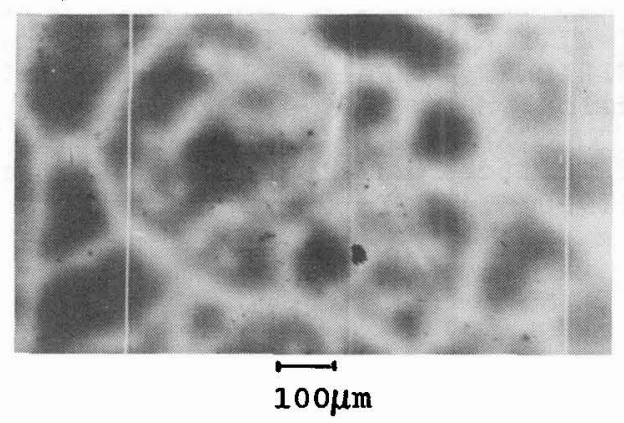

Fig. 7 The bright EBIC contrast of sub-grain boundaries in an $\mathrm{p}-\mathrm{Cd}_{02} \mathrm{Hg}_{08} \mathrm{Te}$ crystal ( $\left.\mathrm{T}=90 \mathrm{~K}\right)$. 
neighboring these defects. This has been observed in $\mathrm{p}-\mathrm{Cd}_{02} \mathrm{Hg}_{08} \mathrm{Te}$ crystals annealed in $\mathrm{Hg}-\mathrm{rich}$ atmosphere where the bright contrast appeared at sub-grain boundaries (Fig.7) [13]. Such treatment can lead to $\mathrm{Hg}$ diffusion along the boundaries and to the formation of inverse conducting layers in their vicinity.

\section{Conclusions}

The results obtained indicate that a potential barrier is formed near extended defects in caTe crystals and the stability of this barriers under electron beam excitation can be high enough. Around the extended defects a region with recombination properties different from those of the defect is formed. This follows from the peculiarities in the contrast dependence on the electron beam energy, beam current and the specimen temperature. The experimental results obtained support the assumption about minority carrier transport along some extended defects in caTe crystals.

\section{References}

/1/ LEAMY H J, J.Appl. Phys. 53 (1982) R51.

/2/ HOLT D B, SEM Microcharacterization of Semiconductors. BY D B Holt and D C Joy (Academ.Press) (1989) 241.

13/ WILSHAW P R, FELL T S, BOOKER G R, Point and Extended Defects in Semiconductors. NATO ASI Series B, ed. by G.Benedek, A.Cavallini and W.Schroter (Plenum Press), 202 (1989) 243.

/4/ WILSHAW. P R, FELL T S, Inst. Phys.Conf.Ser. No 104 (1989) 85.

/5/ SIEBER B, Rev Phys. Appliq., Colloque C6, 24 (1989) C6-47.

/6/ BONDARENKO I E, PANIN G N, YAKIMOV E B, IZV. AN SSSR, ser.Fiz. 52 (1988) 1380 (In Russian).

17/ BLUMTRITT $\mathrm{H}$, PANIN $\mathrm{G} N$, YAKIMOV $\mathrm{E}$ B AND HEYDENREICH $J$, PhYs. stat.Sol. (a) 109 (1988) K3.

/8/ RUSSELL G J, ROBERTSON M J, VINCENT B AND WOODS J, J.Mater.Sci. 15 (1980) 939 .

19/ BUBULAC L O AND TENNANT W E, Appl.Phys.Lett. 52 (1988) 1255.

/10/BONDARENKO I E, YAKIMOV E B, Phys.stat.Sol. (a) 122 (1990) 121.

/11/SIEBER B, PHILIBERT J, Philos. Mag. B55 (1987) 175.

/12/SIEBER B, Philos. Mag. B55 (1987) 585.

113/PANIN G N, YAKIMOV $E$ B, Abstr. of the confer. on Physics and Chemistry of Surfaces and Interfaces in Narrow Gap Semiconductors, Lvov, USSR (1990) 144 (In Russian). 